\title{
A CRIANÇA COMO SUJEITO DE DIREITOS NO PENSAMENTO DE BOAVENTURA DE SOUSA SANTOS: DIÁLOGOS COM A SOCIOLOGIA DA INFÂNCIA E IMPLICAÇÕES PARA A PESQUISA EM EDUCAÇÃO
}

\author{
THE RIGHTS OF THE CHILD IN THE THOUGHT OF BOAVENTURA DE SOUSA \\ SANTOS: DIALOGUES WITH THE SOCIOLOGY OF CHILDHOOD AND \\ IMPLICATIONS FOR RESEARCH IN EDUCATION
}

\author{
Fernanda Michelle Pereira Girão \\ Mestre em Educação \\ Universidade Federal de Pernambuco - UFPE \\ Recife, Pernambuco - Brasil \\ fernanda.michelle@hotmail.com \\ Ana Carolina Perrusi Brandão \\ Doutora em Psicologia Cognitiva \\ Universidade Federal de Pernambuco - UFPE \\ Recife, Pernambuco - Brasil \\ ana.brandao@ufpe.br
}

\begin{abstract}
Resumo: O artigo reflete sobre alguns pilares do pensamento de Boaventura de Sousa Santos tecendo conexões com os Estudos da Criança, sobretudo, no que se refere à Sociologia da Infância em sua vertente crítica. Dessa forma, retomamos conceitos elaborados pelo autor, tais como, a crítica à ciência moderna e a sociologia das emergências, dialogando principalmente com o quadro teórico proposto por Sarmento $(2004$; 2018). No artigo discutimos ainda a concepção de criança como sujeito de direitos e suas implicações para a pesquisa com foco na educação da primeira infância. Por fim, considerando a natureza argumentativa da cadeia de conceitos desenvolvida por Boaventura, que dá espaço ao contraditório e ao enfrentamento da hegemonia de discursos já formulados sobre a infância, sugerimos alguns alinhamentos entre a necessidade de repensar esse segmento geracional e a efetivação das condições para a sua emancipação social. Nessa direção, propomos a superação da visão universalista não apenas em relação à criança, como já tem sido indicado pela Sociologia da Infância crítica, mas também em relação à escola, dando visibilidade a experiências alternativas nesse espaço. Concluímos que o olhar descentralizado sobre a infância em diferentes contextos institucionais, incluindo ambientes escolares com outras formas de organização do tempo e do espaço, com outras lógicas na implementação de seus projetos políticos pedagógicos, pode nos oferecer novos subsídios para a construção de uma Pedagogia da Infância que, no Brasil, constitui um campo de pesquisa emergente.
\end{abstract}

Palavras-chave: Infância. Pesquisa em Educação Infantil. Sociologia da Infância.

\begin{abstract}
The article reflects upon some of the pillars of the thinking of Boaventura de Sousa Santos, making connections with the Childhood Studies, especially with regard to the Sociology of Childhood in its critical approach. We therefore reengage some concepts elaborated by the author, such as the critique of modern science and the sociology of emergencies, interacting mainly with the theoretical framework proposed by Sarmento $(2004 ; 2018)$. We also discuss in the article the concept of the rights of the child and its implications for research focused on early childhood education. Finally, given the argumentative nature of the chain of concepts developed by Boaventura, which allows for contradictions and confrontations of the hegemonic discourse already formulated about childhood, we suggest some alignments between the need of rethinking this generational segment and the fulfillment of the conditions for its social emancipation. Along these lines, we propose to overcome the universal vision not only in relation to the child, as has already been done by the critical Sociology of Childhood, but also in relation to the school, giving visibility to alternative experiences in this space. We conclude that the decentralized view of childhood in different institutional contexts, including school environments with other forms of time and space organization, with other logics in the implementation of its pedagogical political projects can offer new ways for the construction of a Pedagogy of Childhood which, in Brazil, constitutes an emerging field of research.
\end{abstract}

Keywords: Childhood. Research in Early Childhood Education. Sociology of Childhood.

Para citar - (ABNT NBR 6023:2018)

GIRÃO, Fernanda Michelle Pereira; BRANDÃO, Ana Carolina Perrusi. A criança como sujeito de direitos no pensamento de Boaventura de Sousa Santos: diálogos com a sociologia da infância e implicações para a pesquisa em educação. Eccos Revista Científica, São Paulo, n. 56, p. 1-17, e13475, jan./mar. 2021. Disponível em: https://doi.org/10.5585/eccos.n56.13475 


\section{Introdução}

No escopo das políticas públicas para a Educação Infantil no Brasil observa-se, marcadamente, a partir da primeira década do século XXI um movimento mais amplo de redefinição das concepções de educação para a infância, destacando uma imagem afirmativa das crianças. De acordo com essa tendência, documentos oficiais publicados nos últimos anos têm buscado reorientar as concepções e as práticas pedagógicas (e.g., BRASIL, 2006; BRASIL, 2009; BRASIL, 2010), enfatizando o papel do brincar e das interações no cotidiano das crianças e valorizando as vivências permeadas por múltiplas linguagens (musical, plástica, oral, corporal...) nas instituições de Educação Infantil.

Nesse cenário, as culturas infantis também têm se destacado enquanto eixo estruturante do desenvolvimento e, portanto, como linguagem própria da criança na construção de sentidos sobre si e sobre o outro. A dimensão da ludicidade tem, por sua vez, ocupado um lugar importante nas críticas às propostas tradicionais (que se situam no campo das práticas já instituídas) pensadas para a educação das crianças de zero a cinco anos.

No bojo dessa visão crítica percebe-se, entretanto, que o campo da Educação Infantil têm se constituído em meio a intensos debates e algumas contradições, observando-se, por vezes, a coexistência de diferentes olhares que se ancoram numa mesma base. Por exemplo, a ideia da criança como sujeito de direitos tem, notadamente, um fundamento na Sociologia da Infância. No entanto, consideramos que esse campo do conhecimento não pode abarcar apenas uma única possibilidade de entendimento sobre o que se espera em relação às práticas cotidianas na Educação Infantil, tal como argumentaremos aqui.

Uma vez que qualquer discussão relacionada à educação não acontece descolada de questões políticas, observa-se que alguns discursos ganham poder e se consolidam como as narrativas autorizadas. Portanto, sob nosso ponto de vista, a produção do conhecimento no campo da Educação Infantil apresenta-se, atualmente, permeada por contrapontos teóricos, epistemológicos e metodológicos, gerando tensões na busca pela consolidação de uma Pedagogia da Infância. Algumas temáticas (por exemplo, a organização curricular e o ensino ou não - da linguagem escrita) são alvo de calorosos debates abastecidos por discursos centrais (que detêm maior poder nos fóruns acadêmicos) e discursos periféricos (que detêm menor poder, mas que persistem na correlação de forças).

$\mathrm{Na}$ base de todo esse debate, duas questões nos parecem fundamentais: (1) quais os fundamentos da ideia de criança como sujeito de direitos? e (2) Quais as implicações dessa noção para a garantia, de fato, dos direitos desse grupo geracional no âmbito da educação? 
Nesse sentido, o desafio de pensar a educação da primeira infância na contemporaneidade sinaliza para a relevância de pesquisas que se proponham a analisar as categorias "criança", “infância", “escola", “educação" e "cultura" numa perspectiva integradora e crítica.

É exatamente nesse ponto do debate que o pensamento de Boaventura de Sousa Santos tem inspirado um movimento de construção de pedagogias emergentes ligado aos Estudos da Criança. Assim, este campo multidisciplinar que pensa a infância em diferentes contextos, tem formulado contributos importantes para a elaboração de teorias, políticas e caminhos metodológicos para a pesquisa que envolve as crianças e suas questões. Tomam parte nesse campo diversas áreas como a Sociologia, a Antropologia e a Geografia. A Sociologia da Infância, por sua vez, tem se definido a partir de diferentes vertentes. Destacaremos neste artigo a vertente crítica, que

[...] assume como objeto a infância considerando-a, simultaneamente, como uma construção histórica, um grupo social oprimido e uma 'condição social', isto é, um grupo social que vive condições especiais de exclusão, em função do poder paternalista e adultocêntrico" (SARMENTO, 2015, p. 37).

Optamos por trazer, nessa discussão, o recorte da Sociologia da Infância crítica por entender que tal abordagem articula-se fortemente com o quadro teórico e epistemológico desenvolvido por Boaventura em seu questionamento profundo e estrutural da sociedade moderna (SANTOS, 1999; 2002).

Compreendemos que a proposta deste autor fornece subsídios para o movimento de “desinventar" a criança para repensá-la a partir de outra lógica. Esse tem sido o trabalho de diversos pesquisadores situados no chamado "polo lusófono nos estudos da criança". A esse respeito, Regine Sirota afirma que a consolidação desse polo se deu a partir de características específicas compartilhadas entre Portugal e o Brasil. Dentre outros pontos de conexão entre o contexto português e o brasileiro, a autora se refere à existência de uma base comum nesses dois países, visto que em ambos "uma situação de infância, frequentemente considerada como crítica e como problema social, impulsionou uma atenção particular à exclusão da infância e das crianças, dos meninos de rua e do trabalho infantil" (SIROTA, 2010, p. 10 apud SARMENTO, 2015, p. 39).

Desse modo, julgamos que o diálogo entre o enfoque da Sociologia da Infância crítica e o quadro analítico e interpretativo desenvolvido por Boaventura é um caminho interessante para a compreensão da condição do "ser criança" nos contextos da contemporaneidade. Pretendemos, portanto, refletir acerca de alguns pilares do pensamento desse teórico tecendo 
conexões com os Estudos da Criança, sobretudo, no que se refere à Sociologia da Infância em sua vertente crítica, tendo como horizonte um novo olhar sobre a criança enquanto sujeito e objeto de pesquisa.

Os aspectos da teoria formulada por Boaventura sobre os quais nos debruçaremos neste artigo são: 1- a crítica à ciência moderna, 2- a perspectiva argumentativa do direito e a ideia de reinvenção da emancipação social e 3- a abordagem multicultural e o trabalho de tradução. Podemos dizer que o primeiro eixo tem um viés mais epistemológico enquanto o segundo tem um impacto mais político na discussão sobre a infância e, por fim, o terceiro eixo oferece contribuições importantes de natureza metodológica para a investigação científica. Apesar dessa divisão na organização do texto, ressaltamos que os três aspectos citados se relacionam de maneira orgânica na teoria do autor, não sendo possível pensá-los de modo desarticulado em sua proposta de construção de uma teoria crítica pós-moderna.

\section{Os tempos e espaços do "ser criança": a compreensão de um conceito em movimento à luz da crítica à ciência moderna}

Sendo um documento reconhecido por pesquisadores e profissionais da área como um marco importante no Brasil para a consolidação de um novo olhar sobre as crianças, as Diretrizes Curriculares Nacionais para a Educação Infantil (BRASIL, 2010) concebem a criança como

[...] sujeito ativo, histórico e cultural, que nas interações, relações e práticas cotidianas vivencia, constrói sua identidade pessoal e coletiva, brinca, imagina, fantasia, deseja, aprende, observa, experimenta, narra, questiona, constrói sentidos sobre a natureza e a sociedade, produzindo cultura" (p. 14).

No entanto, essa concepção que enfatiza o protagonismo infantil e apresenta os pequenos como sujeitos produtores de cultura é resultado de recentes mudanças na forma de entender a infância.

Na obra intitulada "O desaparecimento da Infância", o americano Neil Postmann discorre sobre a história da infância, retratando o seu surgimento na Grécia Antiga e o seu desaparecimento na Idade Média. Para esse autor, os tempos medievais foram caracterizados pela ausência do sentimento de infância. Não havia, nesse período, uma inquietude direcionada às crianças ou cuidados específicos voltados a esse público. A modernidade, por sua vez, resgatou o conceito de infância a partir da diferenciação entre o adulto e a criança, tendo como critério importante para essa classificação o domínio da escrita, já que a criação da imprensa tipográfica foi um marco desse momento histórico. A distinção entre quem sabia 
ler e quem não sabia indicava quem era criança e quem era adulto. Isso trouxe impactos na educação formal, que passou a priorizar o ensino escrito sistematizado dos conteúdos até então transmitidos principalmente através da oralidade (POSTMANN, 1999).

Embora a perspectiva de que a infância é uma fase distinta do adulto tenha sido resgatada com a modernidade, a criança ainda era tratada a partir do que ela viria a ser ou do que lhe faltava. Precisava, dentre outras coisas, aprender a ler e a escrever para se tornar um adulto e ter acesso ao legado cultural produzido pela humanidade.

Boaventura de Sousa Santos é contundente na sua crítica ao pensamento moderno e à teoria crítica moderna. Para ele, não é possível abordar as questões da contemporaneidade a partir de uma lógica que ainda se ancora nos elementos constitutivos da sociedade moderna. A postura teórica e política do pensador traz, antes de tudo, profundas rupturas com a razão que fundamentou a formação do pensamento moderno, algo que, segundo ele, a teoria crítica até então não foi capaz de fazer. Desse modo, o autor levanta questões dilemáticas em sua análise da realidade social e marca um posicionamento que, ele próprio, resume da seguinte forma:

As promessas da modernidade, por não terem sido cumpridas, transformaram-se em
problemas para os quais parece não haver solução. Entretanto, as condições que
produziram a crise da teoria crítica moderna não se converteram ainda na superação
da crise. Daí a nossa posição transicional, que pode resumir-se assim: enfrentamos
problemas modernos para os quais não há soluções modernas. Segundo uma
posição, que podemos designar por pós-modernidade reconfortante, o facto de não
haver soluções modernas é indicativo de que provavelmente não há problemas
modernos, como também não houve antes deles promessas da modernidade. Há,
pois que aceitar e celebrar o que existe. Segundo outra posição, que designo por pós-
modernidade inquietante ou de oposição, a disjunção entre a modernidade dos
problemas e a pós-modernidade das possíveis soluções deve ser assumida
plenamente e deve ser transformada num ponto de partida para enfrentar os desafios
da construção de uma teoria crítica pós-moderna (SANTOS, 1999, p. 204). Entendemos, portanto, que não há possíveis soluções para os problemas contemporâneos da infância se continuarmos a buscá-las a partir da matriz moderna, uma vez que ela mesma constituiu as condições para o surgimento e o desenvolvimento de tais problemas. Em consonância com o posicionamento de Boaventura, podemos dizer que o "ser criança" na contemporaneidade somente será compreendido por meio de uma epistemologia da controvérsia, da indignação, da argumentação, da esperança que não espera, mas ao contrário, lança-se em direção à crítica ao conhecimento num movimento de desconstrução do que está posto e de construção de novos paradigmas teóricos e políticos em direção à transformação social.

Assumindo a necessidade de um projeto de reinvenção da emancipação social e de renovação do conhecimento crítico-social, apontado por Boaventura, estudiosos da Sociologia 
da Infância crítica têm questionado a concepção de criança fundada no seio da modernidade. Para tanto, a literatura vinculada a tal abordagem tem apontado para a necessidade de construção de um novo senso comum em torno desse conceito. O professor Manuel José Jacinto Sarmento Pereira é um dos expoentes desse movimento em Portugal e postula que o conhecimento moderno sobre as crianças envolve uma tripla falácia:

[...] a visão de uma criança universal, que percorre as mesmas etapas do desenvolvimento e que cresce e se assume como sujeito independentemente do contexto social e cultural em que nasce; a referência ao contexto cultural europeu e norte-americano como espaço balizador dessa pretensa universalidade da criança; a postulação da ideia de que a criança não tem identidade autônoma, mas a identidade "natural" das crianças enquanto seres em transição para a idade adulta, sendo, deste modo, as crianças consideradas seres em transição ("becoming”) e não seres sociais autônomos e completos ("being”) (SARMENTO, 2015, p. 32).

A pretensão da universalidade é abandonada em Boaventura quando o autor enfatiza que não há um único princípio de transformação social, tampouco agentes históricos únicos, tendo em vista que existem também múltiplas formas de opressão e dominação. Da mesma forma, a centralidade da cultura ocidental é desconstruída na medida em que o teórico defende a passagem de uma visão monoculturalista para um olhar multiculturalista, sinalizando para a construção de uma "sociologia das emergências". Em outras palavras, faz-se necessária uma compreensão da realidade social que considere as múltiplas formas de saber e supere os valores universais autorizados pela razão (SANTOS, 1999).

Nessa perspectiva, as crianças são entendidas como seres concretos, situados historicamente e que vivenciam a experiência da infância em contextos diversificados de acordo com a cultura da qual fazem parte, sendo afetadas e também produzindo novas configurações no espaço social a partir dos seus modos particulares de ser e estar no mundo.

Cabe destacar que a Antropologia da Criança tem contribuído significativamente para repensar a normatividade da cultura ocidental reorientando os estudos neste tópico através de pesquisas com crianças em diversos contextos. Ao se debruçar sobre diferentes culturas, os estudos advindos deste campo ressaltam a infância enquanto fase específica vivenciada por sujeitos que não apenas absorvem as características do grupo social no qual estão inseridos, mas que estão em constante interação com esse meio. Nesse sentido, “[...] o que é ser criança, ou quando acaba a infância, pode ser pensado de maneira muito diversa em diferentes contextos socioculturais" (COHN, 2005, p. 22).

Essa área tem desenvolvido, portanto, um arcabouço teórico e epistemológico que aponta o "universo infantil não como um reflexo do mundo adulto, mas, sim como um 
universo qualitativamente diferente e não quantitativamente, como se pensava e se justificava em estudos anteriores" (BUSS-SIMÃO, 2009, p.05). Isso indica que o conceito de infância apesar de ser plural, situado nas diferentes culturas e abarcando não só os elementos pertinentes à faixa etária, mas outras relações como raça, etnia, religiosidade, classe social e gênero, reúne um conjunto de especificidades de uma determinada condição da existência humana. Em outras palavras, ao mesmo tempo em que a infância está referenciada numa pluralidade de aspectos que a compõem e que a situam na realidade concreta dos sujeitos, ela mesma só pode ser compreendia em sua complexidade a partir da sua singularidade, daquilo que lhe é peculiar, que a diferencia, do núcleo comum que define a criança como criança e a revela enquanto sujeito pertencente a um certo grupo geracional.

Ainda no bojo das críticas à racionalidade moderna, é importante discutir o que Sarmento denominou de "administração simbólica da infância", que compreende o conjunto de regras, instituições, prescrições e orientações que normatizaram o que é ser criança baseando-se no princípio da negatividade (SARMENTO, 2004). Segundo o referenciado autor, tais mecanismos foram se desenvolvendo e ficando mais refinados de modo que existe um discurso de proteção e direito das crianças, concretizado na construção de dispositivos legais, mas isso não reverberou na melhoria das condições de sua existência.

Nesse sentido, percebe-se um alinhamento entre o percurso trilhado pela Antropologia da Criança, bem como pela Sociologia da Infância crítica e o pensamento de Boaventura na desconstrução da normatividade e da universalidade impostas pela razão moderna. Tais campos de estudo reconhecem as diferentes possibilidades de infâncias dentro da infância (enquanto categoria geracional) e chama a atenção para a forma como essas diferenças podem revelar e legitimar desigualdades sociais. A seguir, discutiremos sobre a perspectiva argumentativa do direito em Boaventura de Souza Santos e buscaremos refletir sobre como essa abordagem pode contribuir para a compreensão das desigualdades e para a efetivação de uma concepção de criança como sujeito de direitos.

\section{A reinvenção da emancipação social e suas implicações para o direito à infância e a afirmação da criança como sujeito de direitos}

Como já foi dito anteriormente, os Estudos da Criança têm reposicionado o lugar da criança, compreendendo-a como sujeito de direitos e rompendo com as concepções que a colocam em uma posição inferior ancorada nos atributos que lhe faltam para vir a ser um 
sujeito pleno. Tais concepções se expressam por meio de processos de racionalização advindos tanto do conhecimento científico quanto do senso comum fundado na modernidade.

Entretanto, pensar a criança como sujeito de direitos sem problematizar quais os sentidos dessa assertiva em termos políticos e práticos parece-nos o mesmo que plantar uma semente saudável em terras inférteis. Nessa direção, o enquadramento teórico construído por Boaventura na defesa de uma reinvenção da emancipação social traz implicações fundamentais para a reflexão sobre as relações de poder, as formas de dominação e opressão, bem como as possibilidades de sua superação para a transição paradigmática.

Tendo em vista a existência de outros autores que enfocaram as relações de poder como objeto de discussão, cabe esclarecer que a nossa opção pela abordagem de Boaventura decorre do fato de sua teoria considerar a existência de uma multiplicidade de conhecimentos, direitos e poderes. Ao destronar a ciência moderna, o direito estatal e o Estado liberal como únicas fontes válidas de conhecimento, direito e poder, respectivamente, tal estudioso vislumbra diferentes possibilidades de articulação entre esses três fios condutores. Além disso, Boaventura argumenta que cada um deles pode se efetivar através de múltiplos arranjos.

Sendo assim, o autor conceitua o poder como "qualquer relação social regulada por uma troca desigual" (SANTOS, 2002, p. 266). Porém, essas trocas não acontecem de maneira isolada, mas em cadeia, estabelecendo elos e formando o que ele denomina de "constelações de relações de poder". Esse conceito é, particularmente, relevante para a discussão que fazemos aqui dada a necessidade, já pontuada anteriormente, de se apreender a experiência da infância, enquanto categoria geracional, em diferentes contextos. Em outras palavras, somente uma teoria com um espectro de análise tão amplo pode auxiliar na busca por possíveis respostas para os problemas da infância considerando as múltiplas combinações de formas de opressão exercidas sobre as crianças nos vários espaços/tempos onde o ser criança (não) é vivenciado. Ou seja, para os Estudos da Criança é fundamental entender de que forma as trocas desiguais, que se estabelecem no âmbito doméstico, nas ruas, no trabalho, na escola, na mídia, na comunidade, nas questões de gênero, de raça, de etnia, por exemplo, podem afetar esses sujeitos, seus interesses e suas necessidades.

A ideia do direito como uma categoria que não está centralizada no Estado também produz tensões entre os mecanismos de regulação e aqueles que se prestam à emancipação. Nesse contexto, ganha força o direito como prática social, sendo emanado de outras fontes como os movimentos e entidades que representam os diversos segmentos da sociedade. No 
que se refere à infância, tais grupos têm exercido um papel importante na luta pela garantia dos direitos das crianças, dentre eles o direito à educação de qualidade e ao brincar como linguagem específica desse grupo social e eixo estruturante do desenvolvimento humano. Outros grupos têm, inclusive, agregado forças a essa pauta como é o caso dos movimentos feministas, já que existe uma interface entre as formas de opressão exercidas sobre mulheres e crianças, construídas e fortalecidas em torno da cultura do patriarcado.

Ao apresentar pontos de convergência entre a obra de Boaventura e a de Sarmento em sua defesa por uma agenda crítica para os Estudos da Criança, Silva (2015) chama atenção para a imagem da não-criança, perversamente simétrica ao da criança-sujeito-de-direitos. Tal fenômeno se constitui na obrigação que recai sobre as crianças regidas pelo princípio da autonomia, não sendo essa autonomia a consequência da expansão de seus direitos, mas da privação deles. Segundo a autora, “a concepção pós-moderna da criança (sujeito-de-direitos) se baseia na necessidade de que essa categoria seja "despensada", que nos termos de Boaventura significa o processo analítico pelo qual o direito é submetido a um questionamento radical” (SILVA, 2015, p. 116)

Portanto, diferentemente do caminho percorrido pela Sociologia clássica, a Sociologia da Infância crítica assume o desafio de estudar formas de desconstruir e/ou relativizar normas que regulam a infância. Essa perspectiva põe em evidência a necessidade de uma reformulação das relações entre conhecimento e poder para identificar os elos que constituem as cadeias de desigualdade que afetam as crianças, principalmente, aquelas já socialmente excluídas e que enfrentam maiores riscos de serem expropriadas dos seus direitos, dentre eles o direito de ser criança.

\section{A abordagem multicultural e o trabalho de tradução: caminhos metodológicos para a pesquisa com crianças}

Durante um longo período as crianças sequer foram vistas enquanto grupo social pela Sociologia. Após essa fase de invisibilidade a Sociologia clássica começou a incorporar as crianças em suas análises, porém ainda sem uma preocupação em compreender o ponto de vista desses sujeitos sobre as questões que lhes afetam. Nesses termos, a "socialização" passou a ser vista como uma tarefa da educação voltada para as crianças pequenas. As crianças precisavam aprender a se socializar para conviverem bem em sociedade, tornando-se adultos bem adaptados. Para tanto, era necessário que elas fossem submetidas a um processo de interiorização das regras sociais, tendo a escola um papel fundamental nessa transmissão. 
As concepções de "socialização" vinculadas aos pensadores clássicos como Durkheim, ainda hoje muito marcantes na cultura escolar, têm sido insistentemente questionadas pela Sociologia da Infância crítica. Ao analisar esse conceito a partir do entrecruzamento das culturas escolares, culturas da infância e culturas familiares, Barbosa sinaliza que

\footnotetext{
mesmo com as mudanças pedagógicas implementadas nos últimos anos, as escolas conservam esta lógica específica de socialização e defendem apenas um modo de ser, de pensar, de responder, isto é, apenas uma forma de cultura que é reconhecida como a legítima (BARBOSA, 2007, p. 1071).
}

Observando essa problemática com as lentes de Bourdieu, poderíamos dizer que as crianças oriundas das classes populares teriam mais dificuldade em atender às expectativas da escola, visto que nela há uma valorização da cultura erudita com a qual as famílias mais favorecidas economicamente têm maior aproximação. Entretanto, ao reconhecer toda a consistência do pensamento de Bourdeieu e as suas valiosas contribuições para a análise da realidade social, precisamos ressaltar que as questões que envolvem a infância necessitam de um olhar mais específico. Em outras palavras, além da noção mais geral de poder e dominação, existem elementos próprios da construção das condições nas quais se vivencia a infância nos diversos tempos e espaços a serem estudados.

Nessa direção, os Estudos da Criança têm colocado em evidência o silenciamento como um aspecto a ser considerado, pois ele se constitui como uma característica da cultura adultocêntrica e, dessa forma, permeia a experiência da infância muito fortemente em diferentes contextos. Surge, então, uma questão epistemológica e que tem desdobramentos metodológicos importantes: como apreender os sentidos produzidos por um grupo social que foi historicamente silenciado? O movimento feito por Boaventura, ao partir de uma abordagem multicultural chegando à formação das subjetividades, traz contribuições fundamentais para a pesquisa não apenas com as crianças, mas com outros grupos sociais subjugados e inferiorizados. Quando defende o não desperdício da experiência, o autor atribui à Sociologia o papel de enfatizar as práticas, os discursos, os sentidos, os modos de ser e estar no mundo que foram desmerecidos "sob a capa dos valores universais autorizados pela razão" (SANTOS, 1999, p. 206).

Interessa-nos, então, como pesquisadores da infância, uma abordagem que trate não apenas daquilo que está dito de forma explícita mas, fundamentalmente, dos silêncios e das suas causas. Para Boaventura, 
os silêncios, as necessidades e as aspirações impronunciáveis são captáveis por uma sociologia das ausências que proceda pela comparação entre discursos disponíveis, hegemônicos e contra-hegemônicos, e pela análise das hierarquias entre eles e dos vazios que tais hierarquias produzem. O silêncio é, pois, uma construção que se afirma como sintoma de um bloqueio, de uma potencialidade que não pode ser desenvolvida (SANTOS, 1999, p. 206, grifo do autor).

Diante disso e considerando que a violência física e simbólica sofrida pelas crianças ainda é justificada e legitimada em muitos espaços (inclusive e principalmente o doméstico), a investigação científica com crianças precisa dispor de recursos e caminhos metodológicos que permitam desvelar o que está por trás dos mecanismos de opressão. Nessa direção, a Sociologia da Infância crítica tem trabalhado no sentido de evidenciar a atividade e a voz das crianças, bem como os sentidos atribuídos por elas através do estudo do protagonismo infantil, da resistência das crianças (sobretudo, em contextos institucionais), das culturas infantis, dentre outras categorias que permitem um olhar mais amplo e, ao mesmo tempo, mais conectado com as peculiaridades desse grupo geracional.

Evidentemente que as crianças, por serem crianças, compartilham de determinadas facetas da opressão em função do poder paternalista e adultocêntico. Porém, as condições das trocas desiguais não são as mesmas em todas as culturas. Sendo assim, a emergência de um novo paradigma que compreenda a totalidade das infâncias sem desembocar numa perspectiva universalista só pode ser pensada a partir de um "trabalho de tradução", que visa criar formas de inteligibilidade, coerência e articulação entre a multiplicidade e a diversidade. O "trabalho de tradução", proposto por Boaventura, aponta um percurso interessante e, ao mesmo tempo, extremamente desafiador para a pesquisa com crianças. Em paralelo, o professor Manuel Sarmento tem construído avanços significativos na criação dessas lentes de inteligibilidade a partir da reflexão sobre três eixos:

(1) O estudo das culturas infantis, que compreende análises sobre a atividade de simbolização das crianças, seu potencial criativo e a sua disposição para brincar, características dessa fase da vida em diferentes tempos/espaços;

(2) O estudo das interações nos níveis intergeracionais e intrageracionais, que ressalta o caráter relacional do conceito de "geração", através do qual se assumem posições de adulto e criança;

(3) O movimento contra-hegemônico, que busca se posicionar contra as desigualdades (de geração, de classes, de raça, de etnia...) enfrentadas pelas crianças no mundo. 
Para tanto, Sarmento argumenta em favor de um reposicionamento da criança na pesquisa social, de objeto de estudo para sujeito/objeto. Com esse discurso, a voz das crianças sobre as desigualdades e sobre os diferentes temas que envolvem a infầncia ganha especial atenção. E sendo assim, um paradigma emergente em pesquisa com crianças passa a se constituir a partir da escuta desses sujeitos e de recursos metodológicos diferenciados, sobretudo, os recursos visuais que podem revelar o "não dito" e a forma como as crianças são vistas ou não são vistas nas relações sociais. A perspectiva das crianças é considerada fundamental não somente para a interpretação das questões que tocam a infância, mas para a compreensão de toda a dinâmica da sociedade, visto que elas não apenas integram essa rede, mas são sujeitos que interferem nela, produzindo modificações nessa configuração (SARMENTO, 2015, p. 41). Isso significa que, nos espaços em que as crianças estão presentes, as relações seguem uma dinâmica diferenciada dos espaços ocupados apenas por adultos.

Nesse contexto, as "culturas da infância" têm sido foco de investigações partindo da ideia de que as crianças instituem, utilizando-se de uma lógica peculiar, um conjunto de símbolos, de regras e de formas de participação na sociedade (ver, por exemplo, BELTER, 2013; BORBA, 2005; NEVES; CASTANHEIRA; GOUVÊA, 2015). A busca pela compreensão das características específicas desse grupo apontou a brincadeira como elemento estruturante das culturas da infância e como ação altamente complexa, permeada de referências, negociações e noções de valores compartilhados como inclusão, hierarquia, cooperação e liderança.

Todavia, sob nosso ponto de vista, pouca atenção tem sido dada pela pesquisa educacional aos sentidos atribuídos pelas crianças em relação às atividades desenvolvidas na escola. Isso sinaliza que temos um longo caminho a percorrer se pretendemos não desperdiçar as experiências infantis no processo de produção do conhecimento sobre a infância e sobre as relações sociais de maneira mais ampla.

\section{Análises conclusivas e implicações para pesquisas futuras}

Com base no que foi discutido até aqui, é possível estabelecer pontos de articulação entre os constructos teóricos desenvolvidos por Boaventura e a pesquisa social que envolve as crianças, abrangendo tanto dimensões epistemológicas, quanto políticas e metodológicas. No entanto, entendemos que o mencionado autor nos apresenta um horizonte de possibilidades 
que provocam muito mais questionamentos e inquietações do que respostas. Por exemplo, como apreender os interesses e sentidos atribuídos pelas crianças sobre as práticas vivenciadas na escola, sendo ela uma instituição altamente normativa e hierarquizada?; Como capturar as trocas desiguais nas interações com os adultos nesse espaço institucional?; Qual a importância e quais os limites da autoridade do adulto na construção das condições necessárias para que as crianças exerçam o seu protagonismo na escola?; Como pensar em uma relação mais orgânica e solidária entre culturas da infância e cultura escolar?

Consideramos que um caminho a ser percorrido é a superação da visão universalista não apenas em relação à criança, como já tem sido feito contundentemente pela Sociologia da Infância crítica, mas também no que concerne à escola. Percebemos que a crítica à escola numa abordagem universalista (em geral, ressaltando apenas aspectos negativos) tem sido uma característica recorrente em algumas pesquisas ancoradas nos fundamentos da Sociologia da Infância (ver, por exemplo, BARBOSA, 2007; MÜLLER, 2006). Porém, se pretendemos nos orientar por uma base epistemológica multicultural, como nos aponta Boaventura, acreditamos na importância da abertura para a controvérsia, para o conflito, o contraditório, o contra-hegemônico, dando visibilidade a experiências escolares alternativas. $\mathrm{O}$ olhar descentralizado sobre a infância em diferentes contextos institucionais - compreendendo os sentidos construídos e compartilhados em ambientes escolares com outras formas de organização do tempo e do espaço, com outras lógicas na implementação de seus currículos e de seus projetos políticos pedagógicos - pode nos oferecer subsídios para a construção de uma Pedagogia da Infância, que se apresenta como paradigma de pesquisa emergente.

Dessa forma, entendemos que a "ecologia de saberes", defendida por Boaventura, passa pelo aproveitamento dos saberes e fazeres das crianças em diferentes contextos, o que significa que precisamos ampliar o espectro das nossas observações e discussões quando o assunto é educação da primeira infância em ambientes institucionais.

Outro caminho que consideramos importante é assumir a ideia de que o direito à educação não se restringe ao acesso da criança à escola, mas pressupõe o respeito aos seus tempos, aos seus interesses, às suas escolhas, aos seus potenciais; o direito de ser ouvida, de ser compreendida e de engajar-se em atividades significativas de construção de conhecimento sobre o mundo, inseridas em uma rede de interações com adultos e outras crianças. Essa pluralidade de situações requer que os diversos temas ligados à educação das crianças pequenas sejam discutidos mais amplamente na pesquisa e na formação de professores. Há uma tendência na literatura brasileira em tratar a "brincadeira" e o "ensino" como dimensões 
que, necessariamente, excluem-se mutuamente. Alguns autores, porém, (e.g., BRANDÃO, 2009; BRANDÃO; ROSA, 2011) têm questionado essa polarização sob o argumento de que o ensino não precisa andar na contramão da concepção de criança como agente da e na sociedade, sujeito potente, que tem voz e vez na escola e em outros espaços, tal como pontua a Sociologia da Infância. Entendemos que superar essa polarização é, particularmente, importante no contexto brasileiro em que os problemas educacionais contribuem para agravar a enorme desigualdade social presente na nossa sociedade.

Nessa perspectiva, enfatizamos a necessidade de aprofundar a reflexão sobre as experiências das crianças nos ambientes de educação formal, assim como consideramos de extrema relevância para a educação da primeira infância, a elaboração de proposições teóricas e metodológicas que possam analisar as aproximações e distanciamentos entre o ensino, os direitos de aprendizagem e a brincadeira.

Diante do que foi discutido até aqui e considerando os desafios postos à pesquisa científica com crianças, podemos concluir que é possível tecer alinhamentos pertinentes entre a necessidade de repensar esse segmento geracional e a efetivação das condições para a sua emancipação social. Nesse sentido, reforçamos toda a cadeia de conceitos desenvolvida por Boaventura de Sousa Santos, que está baseada em uma abordagem argumentativa em que há espaço para o contraditório e o enfrentamento à hegemonia de pensamentos e discursos já formulados sobre a infância.

Compreendemos, então, a pesquisa que busca elucidar as questões que envolvem a infância numa abordagem crítica como um movimento de "desinventar" a criança, desconstruindo a lógica moderna ocidental para repensá-la a partir de outros pontos de vista, inclusive aquele formulado por elas próprias. O cenário atual brasileiro nos coloca diante de um compromisso ainda maior com um trabalho de teorização e de desdogmatização da ciência e do direito, tendo em vista os embates teóricos que envolvem o campo da pesquisa em Educação Infantil no contexto nacional e as constantes mudanças que vêm se orquestrando no âmbito da legislação voltada para a infância desde a década de 90 .

A abordagem multicultural, defendida por Boaventura, constitui a base para os Estudos da Criança e tem sido incorporada às pesquisas sobre a infância na composição de um campo de estudos extremamente rico, que rompe com as barreiras disciplinares e conta com contribuições de diferentes áreas.

No que concerne à dimensão metodológica, as contribuições da mencionada teoria nos coloca diante da tarefa de enxergar a criança como interlocutora na investigação científica 
sobre a infância, pois "provavelmente as crianças sabem bem mais sobre os adultos e as instituições, embora ainda compreendamos pouco sobre suas ideias acerca das pedagogias, ou sobre o que elas pensam dos adultos e das escolas que criamos pensando nelas e nas suas necessidades" (DELGADO; MÜLLER, 2005, p. 357).

Em síntese, podemos dizer que a teoria crítica pós-moderna, nos termos do pensamento de Boaventura, apresenta muitas inquietações para a pesquisa educacional com a primeira infância considerando as práticas já instituídas e aquelas instituintes de novos saberes e fazeres. Porém, ao apontar a emancipação social não como uma ideia que se encerra em si mesma, mas como "resultados criados e criativos de contradições criadas e criativas" (SANTOS, 2002, p. 269), o autor nos coloca no campo das possibilidades. Sendo assim, a pesquisa sobre e com as crianças se propõe à compreensão exaustiva dos aspectos que instituem o modo "fixação-de-fronteiras" nas relações de poder e, simultaneamente, lança-se à “abertura-de-novos-caminhos" na proposição de novas normatividades para a infância, construídas de forma participativa.

A articulação entre caminhos alternativos ao colonialismo, à hegemonia dos pensamentos, à monocultura, aos universalismos e ao conformismo não é tarefa fácil, como reconhece o próprio Boaventura. Porém, entendemos que esse é um passo importante para a consolidação de relações emancipatórias que favoreçam a construção de redes sociais mais humanas e solidárias, repercutindo na melhoria das condições de existência das crianças e de suas experiências educacionais.

\section{Referências}

BARBOSA, M. C. S. Culturas escolares, culturas de infância e culturas familiares: as socializações e a escolarização no entretecer destas culturas. Educação e Sociedade. Campinas, vol. 28, n. 100 - Especial, p. 1059-1083, out. 2007. Disponível em https://www.cedes.unicamp.br/. Acesso em: 30 jul. 2018.

BELTER. L. "Olhos grandes pra te ver e orelhas grandes pra te ouvir": Culturas infantis na docência da Educação Infantil. 2013. 95 f. Dissertação (Mestrado em Educação nas Ciências). Universidade Regional do Noroeste do estado do Rio Grande do Sul. 2013.

BORBA, A. M. Culturas da infância nos espaços-tempos do brincar: um estudo com crianças de 4-6 anos em instituição pública de educação infantil. 2005. 298 f. Tese (Doutorado em Educação). Universidade Federal Fluminense. Niterói, 2005.

BRANDÃO. A. C. P. A criança de 6 anos no Ensino Fundamental: de onde vem e para onde vai? In: PINHEIRO, A. C. F.; ANANIAS, M. (orgs.) Educação, direitos humanos e 
inclusão social: histórias, memórias e políticas educacionais, João Pessoa: Editora Universitária da UFPB, vol. 2, 2009.

BRANDÃO, A. C. P. ; ROSA, E. C. S. (orgs.). Ler e escrever na educação infantil: discutindo práticas pedagógicas. Belo Horizonte: Autêntica, 2011.

BRASIL. Ministério da Educação/ Secretaria de Educação Básica. Política Nacional de Educação Infantil: pelo direito das crianças de zero a seis anos à educação. Brasília, DF, 2006.

BRASIL. Indicadores de qualidade na Educação Infantil. Brasília, DF, 2009.

BRASIL. Diretrizes curriculares nacionais para a educação infantil. Brasília, DF, 2010.

BUSS-SIMÃO, M. Antropologia da Criança: uma revisão da literatura de um campo em construção. Revista Teias, v.10, n.20, julho de 2009.

COHN, C. Antropologia da Criança. São Paulo: Jorge Zahar, 2005.

DELGADO, A.C.C.; MÜLLER, F. Apresentação: Sociologia da infância: pesquisa com crianças. Educação \& Sociedade, Campinas, v. 26, n. 91, mai./ago. 2005. p. 351-360.

MÜLLER, F. Infâncias nas vozes das crianças: culturas infantis, trabalho e resistência. Educação e Sociedade, São Paulo, v. 27, n. 95, p. 553-573, 2006.

NEVES, V. F. A.; CASTANHEIRA, M. L.; GOUVÊA, M. C. S. de. O letramento e o brincar em processos de socialização na educação infantil: brincadeiras diferentes. Revista Brasileira de Educação. 2015. v. 20, n. 60 jan./mar. p. 215-244. Disponível em:

http://www.scielo.br/pdf/rbedu/v20n60/1413-2478-rbedu-20-60-0215.pdf. Acesso em: 22 mar. 2021.

POSTMAN, N. O desaparecimento da infância. Rio de Janeiro: Graphia, 1999.

SANTOS, B. de S. Por que é tão difícil construir uma teoria crítica? Revista Crítica de Ciências Sociais. n. 54, p. 197-215, jun. 1999. Disponível em:

http://www.boaventuradesousasantos.pt/media/pdfs/Porque_e_tao_dificil_construir_teoria_cri tica_RCCS54.PDF. Acesso em: 30 jul. 2018.

SANTOS, B. de S. A crítica da razão indolente: contra o desperdício da experiência. 4. ed. São Paulo: Cortez, 2002.

SARMENTO, M. J. As culturas da infância nas encruzilhadas da segunda modernidade. In: SARMENTO, M. J.; CERISARA, A. B. Crianças e Miúdos: Perspectivas Sociopedagógicas da Infância e Educação. Porto, Portugal: Asa Editores, 2004.

SARMENTO, M. J. Uma agenda crítica para os estudos da criança. Currículo sem Fronteiras, n. 54, p. 31-49, jan./abr. 2015. Disponível em:

http://www.curriculosemfronteiras.org/art_v15_n1.htm Acesso em: 29 jul. de 2018. 
SILVA, P. L. da. Paradigmas emergentes da Sociologia da Infância: uma aproximação entre Boaventura Santos e Manoel Sarmento. In: NETO, D. G. T. (org.). Escritos interdisciplinares: o conhecimento em Boaventura de Sousa Santos. USA: Laxami Book Publication, 2015. 